\title{
BARBARA FREITAG: as margens da vida e obra
}

\author{
por Sayonara Leal*
}

ROUANET, Sérgio Paulo; SOUSA, Nair Heloísa Bicalho de; COELHO, Maria Francisca Pinheiro (Org.). Itinerários de Barbara Freitag. Brasília: Editora Universidade de Brasília, Finatec, 2005. $174 \mathrm{p}$.

Entre as margens da percepção e da realidade, mediando o diálogo entre conhecimentos filosóficos e científicos encontra-se Barbara Freitag, expressão da intelectualidade brasileira e européia; personalidade que tem percorrido um longo itinerário, buscando compreender as relações sociais e políticas de nosso tempo. Professora do Departamento de Sociologia da Universidade de Brasília durante trinta anos, é um dos expoentes que a Sociologia contemporânea brasileira herdou do processo de emigração de alemães para a América, no período pós II Grande Guerra.

Uma das difusoras do pensamento crítico da Escola de Frankfurt no país, Barbara foi, em abril de 2002, homenageada por ex-alunos, orientandos e colegas de trabalho da Universidade de Brasília num evento que reuniu admiradores da sua obra e história de vida.

Esse debate deu origem ao livro Itinerários de Barbara Freitag, que está dividido em quatro eixos temáticos que refletem os cortes epistemológicos e as etapas de construção da sua carreira acadêmica: Mudança social e política educacional, Teorias da cidade, Psicologia e Sociologia, e Marxismo e Teoria Crítica. O livro é uma

\footnotetext{
* Doutoranda do Departamento de Sociologia da UnB, pesquisadora associada ao Centre Lillois d'Études et de Recherches Sociologiques et Économiques - l'IFRESI, em Lille, na França.
} 
seqüência de depoimentos sobre as contribuições de Barbara Freitag ao campo interdisciplinar das ciências humanas e sociais. Trata-se de uma compilação de comentários em relação à pertinência dos escritos da cientista desde a sua dissertação de mestrado de 1968 até seus trabalhos mais atuais. Configura-se um debate cujo caráter reflexivo e crítico se traduz em elementos fundadores dessa esfera de discussão.

A primeira parte do livro, "Mudança social e política educacional", é formada por três ensaios que trazem à tona os fundamentos da tese de doutorado de Barbara. Em "Educação pobre para pobre: aportes da tese de doutorado de Barbara Freitag", o professor Pedro Demo, do Departamento de Sociologia da UnB, retoma a tese de doutoramento de Barbara, defendida em 1972, na Universidade Técnica de Berlim e publicada na Alemanha em 1975, sob o título A política educacional no Brasil. Segundo Demo, o fato de a pesquisadora morar na época fora do país não a afastou do seu objeto e muito menos a impediu de tecer uma crítica lúcida e pertinente à política educacional brasileira no contexto da Ditadura Militar. Barbara, numa perspectiva marxista, postula em seu trabalho uma relação estreita entre consciência, emancipação e educação. A questão da capacidade cognitiva da criança associada à condição de classe social é um aspecto central da pesquisa desenvolvida pela autora. Ao retomar a tese de Barbara, Pedro Demo revisita alguns dados sobre o sistema público de Educação no Brasil para ratificar fundamentos conceituais trabalhados pela autora. Apesar da atualização de informações e da consideração de uma outra conjuntura política e econômica do País, Demo conclui que ainda, sim, é válida a hipótese de trabalho de Barbara, assim como são atuais alguns dos problemas estruturais no sistema de educação brasileiro, mapeados pela cientista há mais de três décadas.

No texto "Florestan Fernandes: tese de mestrado", a professora Lore Fortes, da Universidade Federal de Goiás, debruça-se sobre a dissertação de mestrado de Barbara, na qual ela articula as contribuições teóricas dos intelectuais Florestan Fernandes, Gilberto Freyre e Celso Furtado para o pensamento social brasileiro. Segundo 
Lore, nesse trabalho, intitulado $O$ desenvolvimento sócio-econômico do Brasil a partir da visão dos cientistas sociais brasileiros, a pesquisadora dá um tratamento crítico e analítico às proposições desenvolvidas por esses autores sobre questões sociais e econômicas históricas da sociedade brasileira, como o problema racial, o planejamento, a industrialização, a educação.

Sem se desviar do tema da educação, objeto intrínseco à obra de Barbara Freitag, Valéria Rodrigues Motta, ex-orientanda de mestrado da homenageada, nos fala sobre "O livro didático em questão". De início, Valéria relata a sua experiência em um grupo de pesquisa liderado por Barbara entre 1985 e 1988. O trabalho tinha como foco a verificação de diferentes métodos de alfabetização na verdade, um olhar crítico sobre o livro didático usado em sala de aula pelos educadores do ensino público. A pesquisa contempla a relação entre psicogênese infantil e rendimento escolar de trezentas crianças matriculadas na rede oficial de ensino, com diferentes níveis socioeconômicos. O campo de pesquisa foram duas cidades de Goiás: Interlândia e Abadiânia. Valéria ressalta o olhar sociológico de Barbara voltado para as condições de aprendizagem das crianças em seu contexto histórico, social, local, específico.

Para encerrar esta primeira parte, Barbara ratifica que os resultados das suas investidas científicas sobre Educação no Brasil apontam para um histórico de déficit de qualidade do ensino médio brasileiro, velhos problemas estruturais que não foram resolvidos mesmo hoje com as políticas públicas implementadas pelo poder competente.

A segunda parte do livro tem como tema "Teorias da cidade" e conta com quatro contribuições. Em geral, os temas abordados nesse tópico referem-se às causas e efeitos do avanço das cidades em conciliação com o fenômeno dos problemas estruturais que incentivam o êxodo rural.

"Cidade e literatura", redigido pela professora Maria Salete Kern Machado, do Departamento de Sociologia da UnB, abre essa 
segunda parte. A professora evoca as contribuições dos estudos da pesquisadora alemã para pensar a urbanidade a partir da literatura numa conjugação que, além de poética, é também reveladora, já que permite a leitura das impressões de artistas e intelectuais sobre as mudanças daquilo que historicamente entendemos como polis. Segundo Maria Salete, dois textos de Barbara sobre cidades ilustram bem as suas posições teóricas sobre o urbano: os ensaios Lisboa e Eça de Queirós e $O$ mito da megalópole na literatura. No primeiro, Barbara olha a partir da "lente" da obra de Eça de Queirós para as mudanças sociais em Portugal tendo como ponto de partida as reformas urbanas que se processaram em Lisboa no final do século XIX. No segundo texto, Barbara oferece rico manancial teóricoconceitual e, a partir de personagens importantes da literatura brasileira, como Macabéa, distingue metrópole e megalópole, desvendando assim mitos de "cidades grandes". Em "A cidade dos homens: a respeito de Barbara Freitag", o professor Brasilmar Ferreira Nunes, do Departamento de Sociologia da UnB, reconhece em Barbara um novo olhar sobre as cidades e suas especificidades e mudanças ao introduzir em seu estudo sobre o espaço urbano o recurso da literatura e da psicologia. Segundo Brasilmar, na ótica de Barbara, a dimensão das cidades, então, não é só espacial e estrutural, mas também está na consciência da sociedade.

"Itinerâncias, nomadismo e exílio: sobre itinerâncias, de Barbara Freitag" é o tema desenvolvido pela professora Angélica Madeira, do Departamento de Sociologia da UnB. Integrante do grupo de pesquisa organizado e dirigido por Barbara Freitag, "Itinerâncias urbanas no Brasil, capitais migrantes, poderes peregrinos, representações nômades", Angélica ressalta a sensibilidade da cientista alemã em agregar ao trabalho teórico e de campo o aspecto da cultura urbana contemporânea e a retomada e diferenciação de conceitos como urbanidade e civilização. O caráter interdisciplinar dos trabalhos de Barbara é, de acordo com Angélica, o que permite fazer incursões mais ousadas ao universo das ciências humanas e sociais e subsidiar processos de rupturas e cortes epistemológicos, muitas vezes necessários. Para Angélica Madeira, a obra de Barbara 
Freitag traz em si o registro de seus "itinerários e percursos" e elementos para a compreensão dos dramas éticos e morais que vivemos em nosso tempo, em meio a recorrentes repressões do sujeito pelas estruturas sociais.

A última contribuição desse capítulo ficou a cargo da professora Nair Heloísa Bicalho de Sousa, do Departamento de Serviço Social da UnB, em "Itinerâncias urbanas: um olhar identitário e multidisciplinar". Nair Bicalho centra seus comentários no fenômeno urbano, na complexidade do espaço físico da cidade e na vida dos moradores. Numa perspectiva sociopolítica, Nair considera que as contribuições de Barbara nos ajudam a compreender as configurações espaciais do urbano e sua relação com o quotidiano dos cidadãos da polis. Afinal, como ratifica Nair, a clivagem entre corpo político e as formas urbanas se constrói a partir de uma concepção de cidade como locus do poder. Nair Bicalho interpreta o trabalho de Barbara sobre as cidades e o processo histórico de configuração dos centros urbanos a partir de uma lógica da diferenciação de classes sociais, modelo excludente e hierarquizado no qual se enquadra Brasília.

Em debate sobre o tema das cidades e suas configurações institucionais e simbólicas, Barbara aponta em Brasília a ausência de formação de um ethos público que possibilite a configuração de espaços urbanos como espaços públicos para reflexões políticas, cujo conteúdo deve estar pautado, sobretudo, na cidadania. Para a autora, no projeto da nova capital do Brasil a questão da cidadania associada ao plano urbanístico não foi contemplada.

$\mathrm{Na}$ terceira parte do livro, três textos tematizam o binômio "Psicologia e Sociologia" na obra de Barbara Freitag. Os autores realizaram uma ampla discussão sobre a formação cognitiva dos sujeitos abordando a fronteira entre pensamento, linguagem e dados socioeconômicos. A primeira explanação versa sobre "Moral e direito: de Antígona a Barbara Freitag”, realizada pelo professor José Geraldo de Sousa Júnior, do Departamento de Direito da UnB. Em sua participação, José Geraldo buscou trazer à tona a discussão pertinente por princípio ao campo do Direito sobre a recorrência da norma moral 
e jurídica na vida social das pessoas. Para o autor, em Itinerários de Antígonas, Barbara recupera a abordagem sobre a presença da norma na vida social desenvolvida por três autores clássicos do pensamento social: Max Weber, Émile Durkheim e Jean Piaget. As normas tanto técnicas, jurídicas ou morais que regem comportamentos e ações nas sociedades podem ser complementares. Nesse caso, o autor sugere um conceito de direito que se traduza na "positivação da liberdade conscientizada e conquistada nas lutas sociais". Numa lógica semelhante sobre a concepção do direito, Rudolf von Iheing (2003, p. 27) postula que o fim do direito é a paz, mas enquanto persiste a injustiça ele não pode prescindir da luta. É no conteúdo ético das normas, na questão moral das relações sociais e nas lutas por emancipação que José Geraldo refere-se a Itinerários de Antígona como um exercício de reflexão sobre o direito e sua dimensão subjetiva.

Ainda pautado no mesmo texto de Barbara Freitag, o professor Luiz Martins da Silva, do Departamento de Comunicação da UnB, considera que o caráter pedagógico da tragédia ressalta conteúdos éticos e morais que podem ser extraídos do trágico destino de Antígona. O não questionamento de regras e normas anteriormente estabelecidas leva a personagem de uma das mais emocionantes tragédias gregas, Antígona, a não fazer uso daquilo que Habermas (1989), a partir da psicogenética de Piaget, afirma ser atributo de todo ser humano: a capacidade da linguagem. A cognição torna o homem capaz de criar repertórios e inovar contextos éticos e morais. Tudo depende da base argumentativa do indivíduo e do potencial dialógico resguardado num espaço discursivo. Mas, Antígona, como mostra Barbara e ratifica Martins, não fez uso de seus atributos naturais e nem daqueles subjetivos, construídos no percurso da vida social. Ela sucumbiu à sua própria crença na estaticidade das normas morais e das leis. Luiz Martins metaforicamente advogando a postura moral de Antígona, põe em pauta a questão sobre as possibilidades de se criar condições efetivas de fala e entendimento em momentos de conflito. 
Em "A influência de Jean Piaget no pensamento de Barbara Freitag", a professora Eliane Veras Soares, do Departamento de Ciências Sociais da UFPE, destaca o aspecto da pesquisa empírica do trabalho desenvolvido por Barbara em Sociedade e consciência: um estudo piagetiano na favela e na escola, de 1980. Para Eliane, nesse texto, Barbara nos oferece uma importante contribuição tanto prática como teórica para pensar a relação entre o processo constitutivo das estruturas de consciência e as estruturas de classe de crianças de baixa renda. O contato com a obra de Piaget foi para Barbara um recurso fundamental para que a cientista social desenvolvesse a sua hipótese e compreendesse que a formação das estruturas cognitivas das crianças é influenciada pela sua condição de classe social, sua experiência escolar e idade. Mas, numa perspectiva ainda de caráter marxista, Barbara ressalta que a gênese do problema está nas condições materiais da família à qual pertence a criança, o que se reflete na sua estrutura psicogenética. Mas não se trata de uma situação irreversível, pelo contrário, a autora postula que mesmo no contexto de precariedade material, a criança pode desenvolver a sua capacidade cognitiva desde que sejam garantidos mecanismos institucionais que amenizem a sua condição de classe.

Em resposta às questões abordadas por esse grupo temático, Barbara inspira-se nas proposições de Habermas (1989) quando este recorre a Piaget e Kohlberg para construir uma teoria crítica, numa perspectiva sociológica, sobre os processos evolutivos da sociedade moderna. Numa postura habermasiana, a mensagem de Barbara nos comunica sobre a reversibilidade de contextos materiais e imateriais que possam oprimir a condição humana.

Aúltima parte do livro, "Marxismo e Teoria Crítica", é composta por duas intervenções que retomam a valorização da racionalidade crítica, tão marcante na obra de Marx, e presente nos textos de Barbara, para estimular uma leitura analítica e reveladora das relações simbólicas que se estabelecem entre os indivíduos nas sociedades modernas capitalistas. 
Em "Diálogo com o marxismo", a professora Maria Francisca Pinheiro Coelho, do Departamento de Sociologia da UnB, faz alusão à participação de Barbara Freitag na coletânea de artigos intitulada Marx morreu: viva Marx! (1993), que ambas organizaram. Tratase de um livro que resgata o pensamento marxista dos escombros do muro de Berlim, ou seja, uma análise conjuntural da derrocada do regime comunista no final da década de 1980. Maria Francisca destaca a crítica feita por Barbara a quatro teses apresentadas por Marx e seus desdobramentos: o determinismo econômico sobre o político, jurídico, social e ideológico; a teoria do valor; a concentração de renda monopolizada por um grupo de capitalistas e as crises cíclicas do capitalismo. Mas, Francisca enfatiza que Barbara, apesar da crítica das matrizes teóricas do pensamento marxista, não as abandona por completo e nem faz apologia ao regime capitalista. Para Barbara, o marxismo como utopia é atual e pertinente quando postula a emancipação do homem num contexto de opressão e miséria no mundo.

Uma importante contribuição de Barbara Freitag ao campo das ciências sociais e humanas no Brasil está na divulgação dos pensadores da Escola de Frankfurt, em especial de Adorno, Horkheimer e Benjamin. Em "Escola de Frankfurt", último texto da coletânea de depoimentos sobre a vida e obra de Barbara, Sérgio Paulo Rouanet discorre sobre a presença da teoria crítica no pensamento da sua companheira e interlocutora intelectual. Rouanet inicia sua exposição traçando os cinco momentos marcantes da história do Instituto de Pesquisa Social, mas conhecido como Escola de Frankfurt. Ao contextualizar os itinerários do grupo de pesquisa no período anterior e pós II Grande Guerra, o autor localiza a gênese dos itinerários de Barbara Freitag, buscando nos princípios da sua formação acadêmica na Alemanha, as influências recebidas pelos contatos diretos com os pensadores da teoria crítica. Desde então, o elemento crítico é constitutivo da sua trajetória de pesquisa e das suas produções acadêmicas. O contato e diálogos com Habermas demonstram a sua preocupação em atualizar as críticas e teorias desenvolvidas pelos autores da primeira geração do Instituto. As 
contribuições conceituais de Habermas para pensar as transformações estruturais e conjunturais do social e da cultura são, para Sérgio Rouanet, um "outro" caminho para reverter quadros de rupturas sociais através de processos comunicativos. A constituição de esferas argumentativas apoiadas na liberdade e no conteúdo ético e moral dos discursos torna possível a participação do indivíduo nos processos da vida social. Na verdade, Rouanet nos fala de uma construção dialógica do consenso a partir de uma ética discursiva que concilie o universal com o particular.

A questão da formação de uma ética discursiva e da superposição da moral em relação ao conflito nos remete ao questionamento elaborado por Luiz Martins sobre eticidade e conflito social.

Em debate desse último bloco de comentários sobre os seus itinerários acadêmicos, Barbara Freitag retoma os princípios da sua formação e revela que apesar de hoje fazer uma releitura dos postulados levantados pelos frankfurtianos da primeira fase do Instituto e do acompanhamento dos novos trabalhos de Habermas, mantém como base de atualização de seus conhecimentos o olhar crítico herdado da tradição frankfurtiana. A autora acredita na capacidade cognitiva humana de superar os seus desafios a partir da inovação de repertórios de vida pela ética discursiva e pela moral que devem orientar os movimentos pela emancipação e as ações do homem.

Para quem conhece Barbara Freitag, como colega de trabalho, orientadora ou professora, sabe que ela sempre enfatiza a importância do pensar criticamente a realidade, valoriza a ação transformadora que vem dos indivíduos, sobretudo a moralidade e a ética, apesar das dilemáticas interações sociais. Ser aluno de Barbara é aproveitar cada palavra; cada gota do conhecimento que ela destila, aproveitar todas as dicas de conceitos e leituras, é ser pontual, assíduo e dedicado. 
Autora de 26 trabalhos publicados no Brasil e na Alemanha, Barbara Freitag aos sessenta e três anos, ainda jovem, bonita, ela percorreu uma longa trajetória desde o Holocausto na Alemanha ao mundo novo. Quem evidencia o seu itinerário pode se perguntar: qual é o segredo? Barbara ensina, orienta, publica, organiza edições, está presente em bancas de doutorado e mestrado, participa de congressos, eventos internacionais, viaja, desfruta das paisagens históricas de Paris, Lisboa e do interior de Minas Gerais. É uma dedicada esposa e companheira intelectual de Sérgio Rouanet, escreve freqüentemente para o Correio Braziliense, coordena pesquisas, dedica-se às problemáticas das grandes cidades, está em dia com os grandes lançamentos da Sociologia, no Brasil e no mundo, e, de vez em quando, ainda se reúne com os amigos.

É difícil abarcar essa personalidade que aflora em um ambiente de conflitos em seu próprio país, migra para longe e encontra nesta terra pouso, abrigo e condições de desenvolvimento da sua intelectualidade, analisando a sua própria experiência histórica. É dotada de uma sabedoria que lhe permite reunir em um só pensamento desde Sócrates, Freud, Piaget a Marx. Brasileira ou alemã? Pouco importa. Ela está aqui e lá, numa terceira margem, como diria Guimarães Rosa, levando a diferentes campos de conhecimento os resultados de suas pesquisas multidisciplinares que apontam realidades contrastantes, mas também, convergentes. "Sou um animal anfíbio. Não pertenço a nenhuma margem. Eu pertenço ao mundo europeu e brasileiro", declara sorridente, Barbara Freitag. ${ }^{1}$

\section{Notas}

1 Entrevista concedida à autora em abril de 2002.

\section{Referências bibliográficas}

IHERING, Rudolf von. A luta pelo direito. São Paulo: Martin Claret, 2003.

HABERMAS, Jurgen. Consciência moral e agir comunicativo. Rio de Janeiro: Tempo Brasileiro, 1989. 